\title{
Buckle Interaction in Textured Deep Subsea Pipelines
}

\author{
by \\ Hassan Karampour and Faris Albermani* \\ School of Civil Engineering \\ The University of Queensland \\ Australlia, 4072 \\ *Corresponding author; f.albermani@uq.edu.au
}

Keywords: Subsea pipelines; Textured pipe; Buckle interaction

\begin{abstract}
:
The paper presents numerical results of lateral buckling, buckle propagation and buckle interaction in textured subsea pipelines and compares these results to those in conventional cylindrical pipelines. Transient and steady states are used to investigate the interaction between lateral and propagation buckling and interaction envelopes are presented for textured and cylindrical pipes. It is shown that the textured pipe offers a superior buckle propagation response that is relatively insensitive to imperfection. The interaction between lateral and propagation buckling in cylindrical and textured pipes makes a substantial reduction in buckle initiation pressure, particularly at lower $D / t$ ratios.
\end{abstract}

\section{Research Highlight:}

- The buckling response of textured and cylindrical subsea pipes is presented and compared

- Under propagation buckling, the imperfection tolerance of textured pipes is contrasted to the acute sensitivity of cylindrical pipes

- The interaction between propagation buckling and lateral buckling in textured pipes is compared to cylindrical pipes

- An interaction design curve is proposed 


\section{Nomenclature}

$D \quad$ nominal outside diameter of pipe

$D_{0} \quad$ pipe mean diameter, $D_{0}=D-t$

$D_{\max } \quad$ measured maximum outside diameter of pipe

$D_{\text {min }} \quad$ measured minimum outside diameter of pipe

$R$

$E \quad$ modulus of elasticity

$E_{t} \quad$ tangent modulus of elasticity

$\sigma_{y} \quad$ yield stress

$M P \quad$ plastic moment of cylindrical pipe

$M P T \quad$ plastic moment of textured pipe

$P_{I}$

buckle initiation pressure of cylindrical pipe

$P_{p}$

$P_{I T}$

buckle propagation pressure of cylindrical pipe

buckle initiation pressure of textured pipe

$P_{P T} \quad$ buckle propagation pressure of textured pipe

$p \quad$ external pressure

$P_{Y} \quad$ Axial crush load of cylindrical pipe

$P_{Y T} \quad$ Axial crush load of textured pipe

$k \quad$ curvature

$k_{c} \quad$ critical curvature

$V \quad$ pipe's volume

$\Delta V \quad$ change in pipe's volume due to external pressure

$\Omega \quad$ ovalization ratio of cylindrical or textured pipe

$a_{o} \quad$ wrinkle imperfection base amplitude

$a_{i} \quad$ wrinkle amplitude bias

$\lambda \quad$ wrinkle imperfection half-wave length

$\lambda_{0} \quad$ lateral imperfection half-wave length

$n$ number of half-waves in wrinkle imperfection

$\bar{\omega} \quad$ localised wrinkle imperfection 


\section{1- Introduction:}

Most of the remaining hydrocarbon reserves are located in remote subsea regions that require ultra-deep (2000-3000m depth) subsea pipelines. At such water depth, collapse is a main design consideration during installation and operation of pipelines. Practical and financial considerations impose constraints on the consequent increase in the pipe's wall-thickness required for deep waters. Furthermore, available mitigation measures, such as buckle-arrestors, come with certain limitations [1].

The restrained axial expansion of a pipeline by seabed friction induces high compression in the already slender structure that can lead to global buckling of the pipeline. Global buckling of pipelines laid on the seabed can be manifested as lateral buckling. On the other hand, subsea pipelines that are trenched may experience upheaval buckling. Although trenching techniques are well established in shallow waters, many issues make them impractical in deep subsea. Hence, lateral buckling is more relevant to deep subsea pipelines.

Deep subsea pipelines are also susceptible to catastrophic buckle propagation that can quickly damage a substantial length of the pipeline. A local buckle can quickly transform the pipe cross section into a dumb-bell form that propagates along the pipeline as long as the external pressure is high enough to sustain propagation. Albermani et al [2] proposed a new pipeline geometry that has the potential to increase the propagation buckling capacity without the associated increase in wall-thickness. The basic idea is to replace the conventional cylindrical pipe by a textured pipe of the same material, diameter and wall-thickness (Fig 1). A conventional pipeline is constructed by joining a number of pipe segments together. To enable joining textured pipe segments, the textured surface must converge to a smooth cylindrical surface at both ends. This is possible to achieve since the textured and cylindrical surfaces are isometric. The textured pipe is cylindrical in global sense with a local textured rather than a smooth wall. A textured pipe with linearized diamond pattern is shown in Fig 2. The basic building block of the diamond pattern is the isosceles triangular facet. The geometry of the textured pipe can be described in terms of four basic parameters as shown in Fig 2. These are; the radius of the equivalent cylinder, $R$, the wall-thickness, $t$, the number of circumferential triangles, $N$, and the base angle of a typical triangular facet, $\alpha$. For the textured pipe shown in Fig $2, N=6$ and the remaining five geometric parameters $(\theta, \lambda, \Delta, h$ and $\gamma)$ are functions of $R, N$ and $\alpha$ as shown in Fig 2.

In deep waters, buckle interaction between lateral and propagation buckling becomes an important design consideration. This interaction is further exasperated due to the inherent imperfection sensitivity of buckle propagation in conventional cylindrical pipes. To date, buckle interaction in deep subsea pipelines has received limited attention [3-5].

In this paper two diameter-to-thickness $(D / t)$ ratios, 28.57 and 42.86, within the range used in deep subsea application are used for both cylindrical and textured pipes as shown in Table 1. Experimental results on buckle interaction in conventional cylindrical pipes was recently reported by Karampour and Albermani [5] where Aluminium pipes with similar D/t ratios were used. Furthermore, for the textured pipes used in this study, $N=6$ and $\alpha=45^{\circ}$ are assumed.

In this work finite element simulation is conducted using ANSYS [6] thin shell, frictionless

contact and target elements (ANSYS elements 181, 174 and 170 respectively). The target/contact elements are used to define the evolving contact between the inner surfaces of 
the pipe wall as it deforms. A von-Mises elastoplastic material definition with isotropic hardening and seven through-thickness integration points are used. The material and section properties of the pipes are listed in Table 1.

\section{2- Axial and flexural response of textured pipe}

It is expected that the textured pipe has a lower axial stiffness than a cylindrical pipe. This is mainly due to the longitudinal undulation of the textured geometry and, to a lesser extent, is due to a smaller cross sectional area. For example, the cross sectional area of a textured pipe with $N=6$ is $95.5 \%$ of the cross sectional area of a cylindrical pipe of the same $D$ and $t$.

On the other hand, the textured pipe can have a substantially higher circumferential stiffness in comparison to cylindrical pipe. The axial and circumferential stiffness and the stress distribution in a textured pipe under axial and hydrostatic pressures have been presented by Khalilpasha and Albermani [7].

To investigate buckle interaction in textured pipes, it will be useful first to compare the structural response of a textured pipe under axial and pure bending conditions to that of a conventional cylindrical pipe.

\section{Axial response:}

A shell finite element model of a short pipe (length, $L=100 \mathrm{~mm}, L / D<4$ ) is used here. Axial shortening is imposed at one end while the other end is restrained. The response is presented in Fig 3a in terms of the resulting axial reaction at the restrained end, $P$, versus the imposed axial strain $\varepsilon$ (imposed axial shortening divided by $L$ ). The axial force is normalised by the squash load $P_{Y}$ of a cylindrical pipe with the same $D / t$ ratio (Table 1 ). Fig 3 a clearly shows that the textured pipe offers lower axial rigidity in comparison to a corresponding cylindrical pipe. Furthermore, due to the inherent coupling between membrane and flexural actions in the textured pipe, the ultimate load of the textured pipe is lower than the squash load of a corresponding cylindrical pipe, particularly for high $D / t$ ratio. Based on the linear part of the response shown in Fig 3a, the ratio of the axial rigidity of the textured to cylindrical pipes are listed in Table 1.

\section{Pure bending response:}

A simple $1.8 \mathrm{~m}$ span of the pipe under uniform bending is used here. Using symmetry, a shell finite element model of half the span is developed where a couple is applied at a master node at the far end. The master node is connected to the circumferential nodes using ANSYS rigid link element (MPC-184). The induced bending moment is obtained from integrating the axial stress at the near end (mid-span) and the resulting curvature is calculated from dividing the rotation at the master node by the model length.

To control the non-linear FE analysis (for both textured and cylindrical pipes), a localised wrinkle imperfection $\bar{\omega}$ is imposed on the compression side of the pipe at mid-span [8]

$$
\bar{\omega}=-\frac{D}{2}\left[a_{o}+a_{1} \cos \left(\frac{\pi x}{n l}\right)\right] \cos \left(\frac{\pi x}{l}\right) \quad 0 \leq x \leq n l
$$


where the imperfection half-wave length $l=0.165 D$, number of half-waves $n=11$ and the base amplitude $a_{0}=2 \Omega$ with amplitude bias, $a_{1} / a_{0}$, of $20 \%$ towards mid-span, where $\Omega$ is ovalization ratio defined as

$$
\Omega=\left(D_{\max }-D_{\min }\right) / D
$$

The obtained moment-curvature (normalized) response is shown in Fig $3 b$ for cylindrical and textured pipes under pure bending. As seen in Fig $3 b$, the results for the cylindrical pipes agree well with experimental results reported in [5]. The moment, $M$, is normalised by the corresponding plastic moment $M p$ of cylindrical pipes (Table 1) and the curvature $k$ is normalised by the critical curvature $k_{c}$ (Table 1), where

$$
\kappa_{c}=t / D_{0}^{2}
$$

According to Fig $3 \mathrm{~b}$ the textured pipes exhibit comparable flexural rigidity to corresponding cylindrical pipes, particularly at lower $D / t$ ratio. However, the ultimate moment capacity of the textured pipe is lower than that of a corresponding cylindrical pipe. This is due to the effect of local bending in the textured pipe in addition to lower plastic moment capacity $M_{P T}$ (about $87 \%$ of $M_{p}$, Table 1). The curvature range shown in Fig $3 \mathrm{~b}$ is comparable to the expected curvature in pipelines under lateral buckling [4, 9]. Based on the linear part of the response shown in Fig $3 \mathrm{~b}$, the ratio of the flexural rigidity of the textured to cylindrical pipes are listed in Table 1.

Fig 4 shows vector plot of principal stresses $\left(\sigma_{1}\right.$ and $\left.\sigma_{3}\right)$ at a hexagonal panel located on the tension-side of a textured pipe $(D / t=28.57)$ subjected to pure bending at a normalised curvature of $k / k_{c}=0.06$. The longitudinal tensile stress $\sigma_{l}$ and hoop compressive stress $\sigma_{3}$ are shown at the middle, inner and outer surfaces of the panel and highlight the extent of local bending in the panel. The maximum values of these stresses at mid-surface are about $30 \%$ higher than those in a cylindrical pipe.

\section{3- Buckle propagation:}

Buckle propagation is a snap-through phenomenon that can be triggered by a local buckle, ovalization, dent or corrosion in the pipe wall. The resulting buckle quickly transforms the pipe cross-section into a dumb-bell shape that travels along the pipeline as long as the external pressure is high enough to sustain propagation. A typical propagation response in a cylindrical pipe is shown in Fig 5, depicted in terms of the applied external hydrostatic pressure against the pipe's volume change $(\Delta V / V)$. The response is characterised by the pressure at which the snap-through takes place (the initiation pressure $P_{I}$ ) and the pressure that maintains propagation (the propagation pressure $P_{p}$ ) which is a small fraction of $P_{I}$. Experimental investigations and finite element simulations of buckle propagation in cylindrical pipelines have been presented by a number of researchers $[2,10-12]$.

\section{3a- Cylindrical pipes:}


Nonlinear shell finite element simulation of buckle propagation response of the pipes shown in Table 1 is conducted using ANSYS [6]. Target/contact elements are used to define the contact between the inner surfaces of the pipe wall as it deforms into a dog-bone shape. A pipe segment with a length $L>50 D$ is used and one half $(\pi)$ of the pipe in the circumferential direction is adopted using symmetry. Initial imperfection in the form of ovalization is introduced by conducting a linear analysis under a patch external pressures over an area one $D$ long and $\pi / 10$ wide in the circumferential direction. The patch load is adjusted to obtain the required ovalization (eq 2). The updated geometry is then used in the following nonlinear analysis to simulate buckle propagation.

The FE prediction of initiation and propagation, $P_{I}$ and $P_{p}$, pressures are listed in Table 2 for intact pipes $(\Omega \approx 0)$ and for dented pipes with initial ovalization $\Omega$ of $0.1 \%$ and $1 \%$ for $D / t=42.86$ and 28.57 respectively. The full propagation response of the dented pipes is shown in Fig 6. The results in Table 2 highlight the sensitivity of $P_{I}$ (but not $P_{p}$ ) to initial imperfection in cylindrical pipes. For intact pipes, it was necessary to introduce a very small ovalization $(\Omega$ $=0.01 \%$ ) in order to control the nonlinear analysis.

\section{3b- Textured pipe}

FE model similar to the one described in the previous section but using the full circumference $(2 \pi)$ is generated for the textured pipes listed in Table 1. Initial ovalization is introduced by imposing an external pressure on a single hexagonal panel to produce a radial displacement, $\zeta$, at its apex. The normalised local imperfection $\psi=\frac{\zeta}{\Delta}$ can be related to the ovalization ratio $\Omega$

$$
\Omega=\frac{D_{\max }-D_{\min }}{D}=\frac{1}{2}\left(1-\cos \frac{\pi}{N}\right) \psi
$$

where $\Delta$ is the amplitude of undulation as shown in Fig 2.

The FE prediction of initiation and propagation, $P_{I T}$ and $P_{p T}$, pressures are listed in Table 2 and the full propagation response is shown in Fig 6. For the same $\Omega$, the $P_{I T}$ of the textured pipe is $137 \%$ and $187 \%$ higher than that of the corresponding cylindrical pipes, $P_{I}$, for $D / t 28.57$ and 42.86 respectively. Similarly, a substantial increase in propagation pressure $P_{p T}$ is observed for the textured pipes (191\% and $240 \%$ for $D / t 28.57$ and 42.86 respectively). Since buckle propagation is proportional to $(t / D)^{2}$, the increase in $P_{p T}$ can be translated to increasing the thickness of the conventional cylindrical pipes, $D / t 28.57$ and 42.86 , by $38 \%$ and $55 \%$ respectively.

Furthermore, $P_{I T}$ results in Table 2 show that the textured pipe is relatively insensitive to imperfection in comparison to cylindrical pipe. These attributes; substantially higher initiation and propagation buckling pressures and more tolerance to imperfections, make the textured pipe a favourable contender for deep subsea application.

The deformed shape of the cylindrical and textured pipes during buckle propagation is shown in Fig 7. While there is similarity between the two, the plastic deformation in the textured pipe is more defused around the cross section in comparison to the cylindrical pipe.

\section{4- Lateral Buckling:}


Deep subsea pipelines are usually laid, rather than trenched, on the seabed. Hence lateral, rather than upheaval, buckling is the dominant global buckling mode. The lateral buckling of the cylindrical and textured pipes listed in Table 1 is considered in this section.

Nonlinear finite element analysis is conducted using ANSYS [6]. The pipe is modelled as a beam on a rigid frictional foundation. A cubic beam element (BEAM 188) is used to model cylindrical pipes while a full shell model is used for the textured pipes.

The lateral drag force from the seabed is modelled using nonlinear spring elements (COMBIN39). In order to ensure that the spring element imposes only a lateral drag force on the pipe, the displacement component parallel to the pipe's longitudinal direction at the boundary node of the spring element is coupled with that of the corresponding node on the pipe. Friction in the longitudinal direction of the pipe is not considered since lateral buckle is entirely controlled by the lateral drag $[5,13,14]$.

Fig 8 shows a normalized bilinear constitutive model adopted to represent the seabed lateral drag force, $F$. According to this model, the peak drag force is mobilized at a lateral displacement, $\delta$, equal to the pipe's diameter $D$ where $\mu$ and $m$ are soil friction and submerged self-weight per unit length of the pipe, respectively ( $\mu$ and $m$ are assumed to be the same for cylindrical and textured pipes).

An initial global geometric imperfection with amplitude $\Delta_{o}=4 D$ and a sinusoidal half wave length $\lambda_{0}=200 D$ is assumed $\left(\Delta_{0} / \lambda_{0}=0.02\right)$. In order to have adequate thermal feed-in length for evolution of lateral buckling, the length of the FE model of the pipe is taken as $8 \lambda_{0}$. Due to symmetry, a half-model $\left(4 \lambda_{0}\right)$ is used in the analysis. Assumed soil friction $\mu=0.7$ and submerged self-weight $\mathrm{m}=14.1 \mathrm{~N} / \mathrm{m}$ (with coating, for all pipes in Table 1). The axial compression force is applied by incrementing the longitudinal displacements at the far end of the model. The resulting axial force and bending moment are calculated by integrating the induced reactions at the near end (the crown).

Figs $9 \mathrm{a}$ and $\mathrm{b}$ show the normalised axial compression force $P / P y$ in the buckle and the normalised crown's bending moment $M / M_{p}$ against normalised crown's lateral displacement $\delta / D$ for both cylindrical and textured pipes. The results for textured and cylindrical pipes are normalised by $P_{y}$ and $M_{p}$ of the corresponding cylindrical pipe. Fig 9a shows that the ultimate axial load occurs at a crown lateral displacement in the range of $1-2 D$ for both textured and cylindrical pipes. For higher D/t ratio, a lower ultimate load is obtained for the textured pipe in comparison to a cylindrical pipe. Fig $9 \mathrm{~b}$ highlights the excessive bending associated with lateral buckling and shows that the responses of the textured and cylindrical pipes are comparable.

\section{5- Buckle Interaction:}

In deep waters, the excessive bending associated with lateral buckling (Fig 9b) can precipitate catastrophic buckle propagation in pipelines. Recently, Karampour et al presented a compact numerical modelling approach and experimental results for buckle interaction in deep subsea cylindrical pipelines [4]. In their approach, a relatively short segment of the pipeline in the vicinity of the crown point of global buckle (lateral or upheaval) is used. Theoretical buckle interaction curves for the same cylindrical pipes shown in Table 1 were presented in their study that show a substantial reduction in initiation pressure $P_{I}$ due to interaction [4]. Two scenarios 
were considered, a transient state $(k-p)$ and a steady state $(p-k)$. Under transient state the pipe is bent to a certain curvature $k$ then the external hydrostatic pressure $p$ is incremented until propagation response is obtained. Under steady state, a certain ratio of initiation pressure (Table 2, $P_{I}$ or $\left.P_{I T}\right)$ is applied followed by incremental application of bending moment until the ultimate capacity is reached.

Nonlinear shell FE analysis is conducted here to simulate buckle interaction under transient and steady states using the approach described in [4]. For both cylindrical and textured pipes, a $1.8 \mathrm{~m}$ long pipe segment is used with initial wrinkling imperfection (eq 1) imposed at the compression side at mid-span using $\Omega=1.0 \%$ and $0.1 \%$ for $D / t=28.57$ and 42.86 , respectively. Using symmetry, a half-span model is used and for cylindrical pipes, a half-circumference $(\pi)$ model is utilised as well.

For transient $k-p$ state, the obtained initiation pressure $p_{I}$ under interaction is normalised by the initiation pressure, $P_{I}$, of the corresponding cylindrical pipe with the same initial $\Omega(0.1$ or $1 \%$ from Table 2, no interaction $\left.M / M_{p}=0\right)$. Fig 10 shows $p_{I} / P_{I}$ against normalised bending moment $\left(M / M p\right.$ for cylindrical and $M / M p_{T}$ for textured pipes) under transient state. Higher reduction in initiation pressure is expected at higher bending moment. The textured pipe offers higher initiation pressure under interaction, $p_{I}$, than a corresponding cylindrical pipe, however, this difference diminishes at higher bending moment.

Under steady state condition, the external hydrostatic pressure is incremented to a certain level (50, 70 and $90 \%$ used here) of the pipe's initiation pressure, $P_{I}$ or $P_{I T}$ (Table 2, no interaction) with the same initial $\Omega(0.1$ or $1 \%)$. While maintaining the external hydrostatic pressure at the desired level, a couple at the far end of the pipe is incrementally applied. As the applied couple is increased, PCG (Preconditioned Conjugate Gradient) solution strategy [6] is invoked to control the nonlinear solution. The moment at which the solution diverges is taken as the ultimate moment capacity of the pipe. Fig 11 shows the normalised moment-curvature response at different levels of applied external pressure $p$ for both $D / t$ ratios. Keeping in mind that $P_{I T} / P_{I}$ ranges from 1.37 to 1.87 ( $\mathrm{Sec} 3 \mathrm{~b}$ ) while $M p_{T} / M p$ is about 0.87 . Based on this, Fig 11 shows that under similar external pressure $p$ the achieved normalized moment capacity for the textured pipe is about the same or higher than that for a corresponding cylindrical pipe.

The results using transient $k$-p and steady $\mathrm{p}-k$ states are combined into normalised interaction envelopes as shown in Fig 12. For cylindrical pipes the critical external pressure $p$ is normalised by the initiation pressure $P_{I}$ of unbent pipe $(M / M p=0)$ with the same initial $\Omega$. The same is followed for textured pipes by normalising with $P_{I T}$.

For cylindrical pipes, Fig 12 shows that at both $D / t$ ratios, steady state $(p-k)$ is the critical envelope when $M / M p>0.62$. At lower $M / M p$, transient state $(k-p)$ is the critical envelope at lower $D / t$ ratio while not much difference between the two states is observed at higher $D / t$ ratio. According to Fig $3 b$, normalised $M / M p=0.62$ corresponds to a normalised curvature $k / k_{c}$ of around $10-15 \%$.

For textured pipes, Fig 12 shows that for both $D / t$ ratios, a transition from critical transient state to critical steady state occurs around $M / M p_{T}$ of $0.65-0.7$ which corresponds to a normalised curvature $k / k_{c}$ of around $20-25 \%$ (Fig 3b). Accordingly, for $M / M p_{T}$ below 0.7 , the textured pipe can accommodate higher external pressure than conventional cylindrical pipe since $P_{I T} / P_{I}$ ranges from 1.37 to 1.87 . At higher $M / M p_{T}$ ratio, the capacity of the textured pipe to 
accommodate external pressure is comparable or slightly below that of a corresponding cylindrical pipe.

\section{6- Concluding remarks:}

The response of textured pipes under buckle propagation and lateral buckling is presented and compared to that of cylindrical pipes of the same $D / t$ ratios. It is shown that the textured pipe offers a superior buckle propagation response that is relatively insensitive to imperfection. Under lateral buckling, excessive bending is expected in textured and cylindrical pipes and the response of both pipes is, to some extent, comparable. The lateral/propagation buckle interaction is treated by considering a pipe segment (textured or cylindrical) in the vicinity of the crown point of lateral buckling. Both transient and steady states of interaction are considered. It is shown that the interaction between lateral and propagation buckling in cylindrical and textured pipes makes a substantial reduction in buckle initiation pressure, particularly at lower $D / t$ ratios. Under transient state, the interaction response of the textured pipe is superior to cylindrical pipe, particularly at lower moment ratio. The interaction response under steady state and at high moment ratio is comparable for both pipes. 


\section{7- References}

1. Kyriakides, S., Efficiency Limits for Slip-on Type Buckle Arrestors for Offshore Pipelines. Journal of Engineering Mechanics, 2002. 128(1): p. 102-111.

2. Albermani, F., H. Khalilpasha, and H. Karampour, Propagation buckling in deep subsea pipelines. Engineering Structures, 2011. 33: p. 2547.

3. Nystrom, P.R., et al., 3-D dynamic buckling and cyclic behaviour of HP/HT flowlines. Vol. 2. 1997. 299-307.

4. Karampour, H. and F. Albermani, Buckle Interaction in Deep Subs Pipelines. ThinWalled Structures, 2013. In Press.

5. Karampour, H. and F. Albermani, Experimental and numerical investigations of buckle interaction in subsea pipelines. Engineering Structures, 2013. Submitted.

6. $\quad$ ANSYS 14.0 Release, A.I.: 275 Technology Drive, Canonsburg,PA 15317.

7. Khalilpasha, H. and F. Albermani, Textured deep subsea pipelines. International Journal of Mechanical Sciences, 2013. 68(0): p. 224-235.

8. Ju, G.T. and S. Kyriakides, Bifurcation and localization instabilities in cylindrical shells under bending - II. Predictions. International Journal of Solids and Structures, 1992. 29(9): p. 1143-1171.

9. Karampour, H., F. Albermani, and J. Gross, On lateral and upheaval buckling of subsea pipelines. Engineering Structures, 2013. 52(0): p. 317-330.

10. Kamalarasa, S. and Calladine CR, Buckle propagation in submarine pipelines. International Journal of Mechanical Sciences, 1988. 30((3-4)): p. 12.

11. Palmer, A.C. and J.H. Martin, Buckle propagation in submarine pipelines. Nature, 1975. 254(5495): p. 3.

12. Gong, S., et al., Buckle propagation of offshore pipelines under external pressure. Marine Structures, 2012. 29(1): p. 115-130.

13. Maltby, T.C. and C.R. Calladine, An investigation into upheaval buckling of buried pipelines--II. Theory and analysis of experimental observations. International Journal of Mechanical Sciences, 1995. 37(9): p. 965-983.

14. Tvergaard, V. and A. Needleman, On localized thermal track buckling. International Journal of Mechanical Sciences, 1981. 23(10): p. 577-587. 


\section{List of Table Captions:}

Table 1: Material and section properties

Table 2: Buckle initiation and propagation pressures (no interaction)

\section{List of Figure Captions:}

Figure 1: A cylindrical and textured pipes

Figure 2: Geometric parameters for a textured pipe

Figure 3: Normalised axial and flexural response of textured and cylindrical pipes

Figure 4: Principal stress vectors in a textured pipe under pure bending

Figure 5: Experimental buckle propagation response in a cylindrical pipe

Figure 6: A comparison of buckle propagation response in textured and cylindrical pipes

Figure 7: Deformed shape under buckle propagation in cylindrical and textured pipes

Figure 8: Bilinear model for seabed lateral drag force under lateral buckling

Figure 9: Lateral buckling response: a) axial load vs lateral displacement, b) crown bending moment vs lateral displacement

Figure 10: Buckle interaction under transient state

Figure 11: Buckle interaction under steady state

Figure 12: Normalised interaction envelopes 
Table 1

\begin{tabular}{|c|c|c|c|c|c|c|c|c|c|c|c|c|}
\hline \multirow[b]{2}{*}{$\mathrm{D} / \mathrm{t}$} & \multirow[b]{2}{*}{$\begin{array}{c}\mathrm{D} \\
(\mathrm{mm})\end{array}$} & \multirow[b]{2}{*}{$\begin{array}{c}\mathrm{t} \\
(\mathrm{mm})\end{array}$} & \multirow[b]{2}{*}{$\begin{array}{c}\mathrm{E} \\
(\mathrm{GPa})\end{array}$} & \multirow[b]{2}{*}{$\frac{E_{t}}{E}$} & \multirow[b]{2}{*}{$\begin{array}{c}\sigma_{y} \\
(\mathrm{MPa})\end{array}$} & \multirow[b]{2}{*}{$\begin{array}{c}\mathrm{k}_{\mathrm{c}} \\
\times 10^{-4} \\
(1 / \mathrm{mm})\end{array}$} & \multicolumn{2}{|c|}{ Cylindrical } & \multicolumn{2}{|c|}{ Textured } & \multicolumn{2}{|c|}{$\begin{array}{c}\text { Rigidity ratio } \\
\text { Textured/Cylindrical }\end{array}$} \\
\hline & & & & & & & $\begin{array}{c}\mathrm{P}_{\mathrm{Y}} \\
(\mathrm{kN})\end{array}$ & $\begin{array}{c}\mathrm{M}_{\mathrm{P}} \\
(\mathrm{kN}-\mathrm{mm})\end{array}$ & $\begin{array}{l}\mathrm{P}_{\mathrm{YT}} \\
(\mathrm{kN})\end{array}$ & $\begin{array}{c}\mathrm{M}_{\mathrm{PT}} \\
(\mathrm{kN}-\mathrm{mm})\end{array}$ & Axial & Flexural \\
\hline 28.57 & 25.40 & 0.90 & 69.0 & 0.0217 & 90.0 & 15.0 & 6.23 & 48.62 & 5.94 & 42.10 & 0.74 & 0.97 \\
\hline 42.86 & 38.10 & 0.90 & 69.0 & 0.0217 & 90.0 & 6.5 & 9.47 & 112.09 & 9.04 & 97.07 & 0.62 & 0.91 \\
\hline
\end{tabular}

Table 2

\begin{tabular}{|c|c|c|c|c|c|}
\cline { 3 - 6 } \multicolumn{2}{c|}{} & \multicolumn{2}{c|}{ Cylindrical Pipe } & \multicolumn{2}{c|}{ Textured Pipe } \\
\hline \multirow{2}{*}{$\mathrm{D} / \mathrm{t}$} & $\Omega$ & $\begin{array}{c}\mathrm{P}_{\mathrm{I}} \\
(\mathrm{kPa})\end{array}$ & $\begin{array}{c}\mathrm{P}_{\mathrm{P}} \\
(\mathrm{kPa})\end{array}$ & $\begin{array}{c}\mathrm{P}_{\mathrm{I}} \\
(\mathrm{kPa})\end{array}$ & $\begin{array}{c}\mathrm{P}_{\mathrm{P}} \\
(\mathrm{kPa})\end{array}$ \\
\hline \multirow{2}{*}{28.57} & 0.0 & 6785 & 721 & 7731 & 1377 \\
\cline { 2 - 6 } & 1.0 & 4890 & 721 & 6677 & 1377 \\
\hline \multirow{2}{*}{42.86} & 0.0 & 2100 & 279 & 3854 & 671 \\
\cline { 2 - 6 } & 0.1 & 2038 & 279 & 3806 & 671 \\
\hline
\end{tabular}




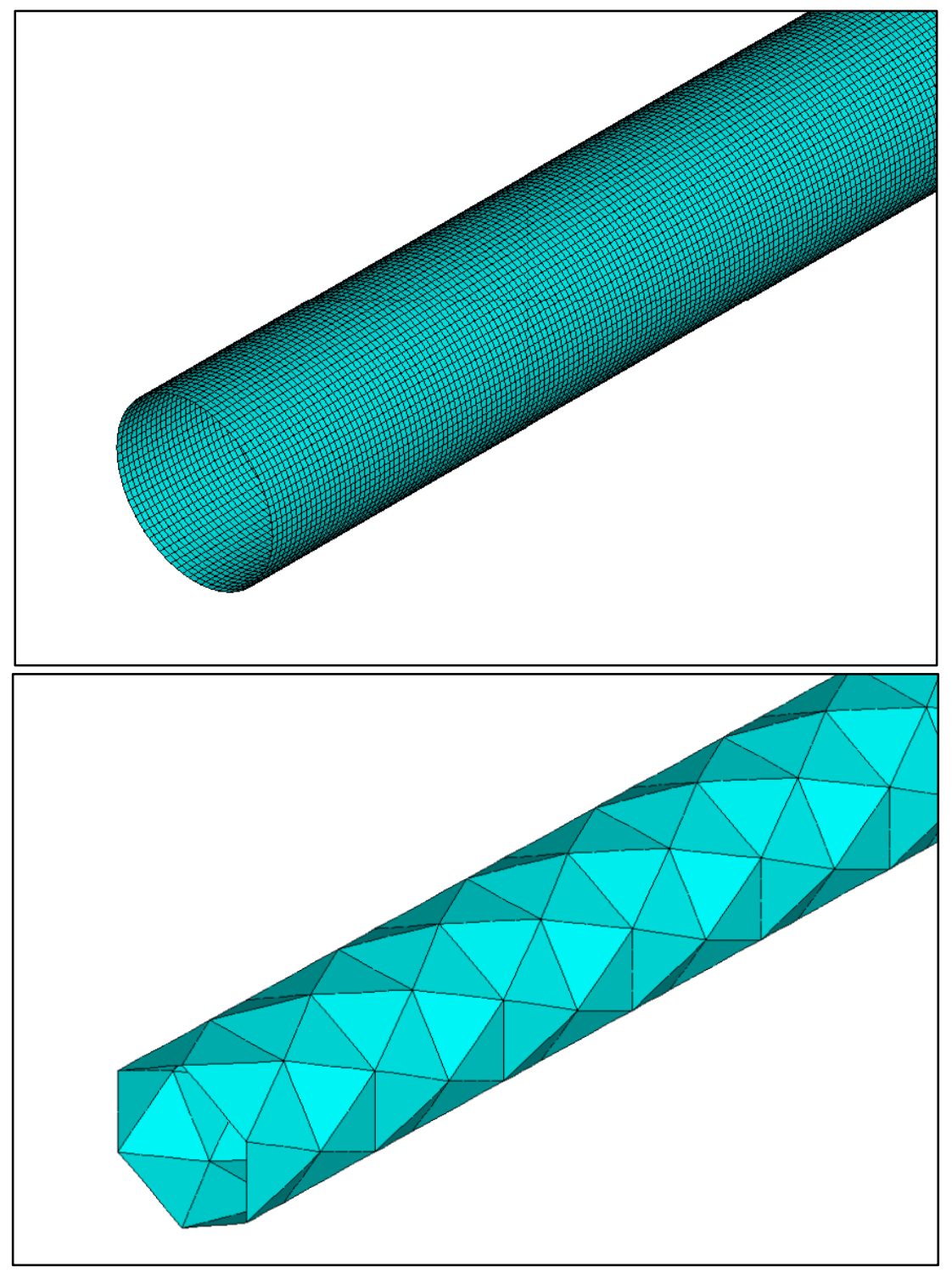

Figure 1 


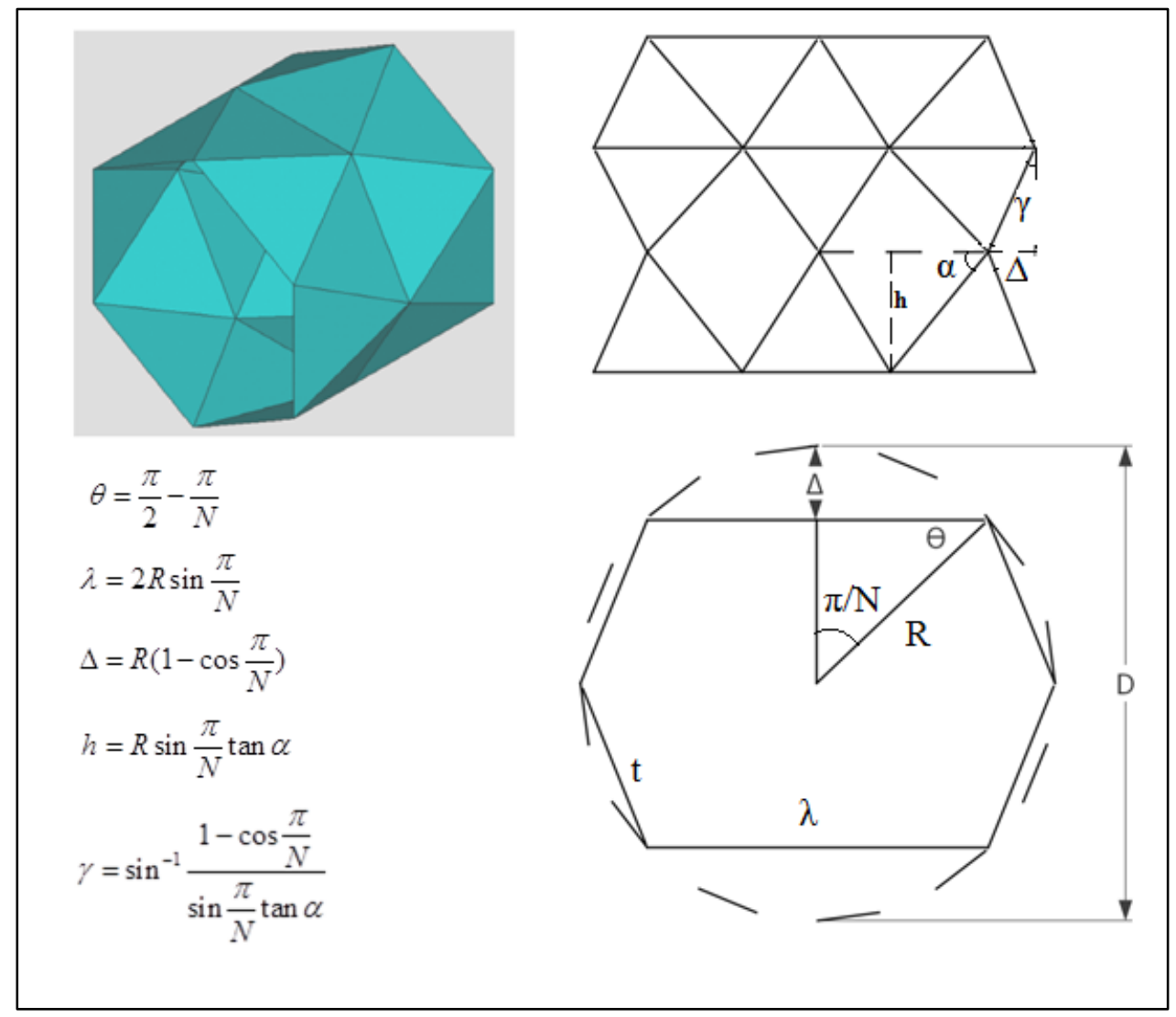

Figure 2 
$\frac{P}{P_{Y}}$

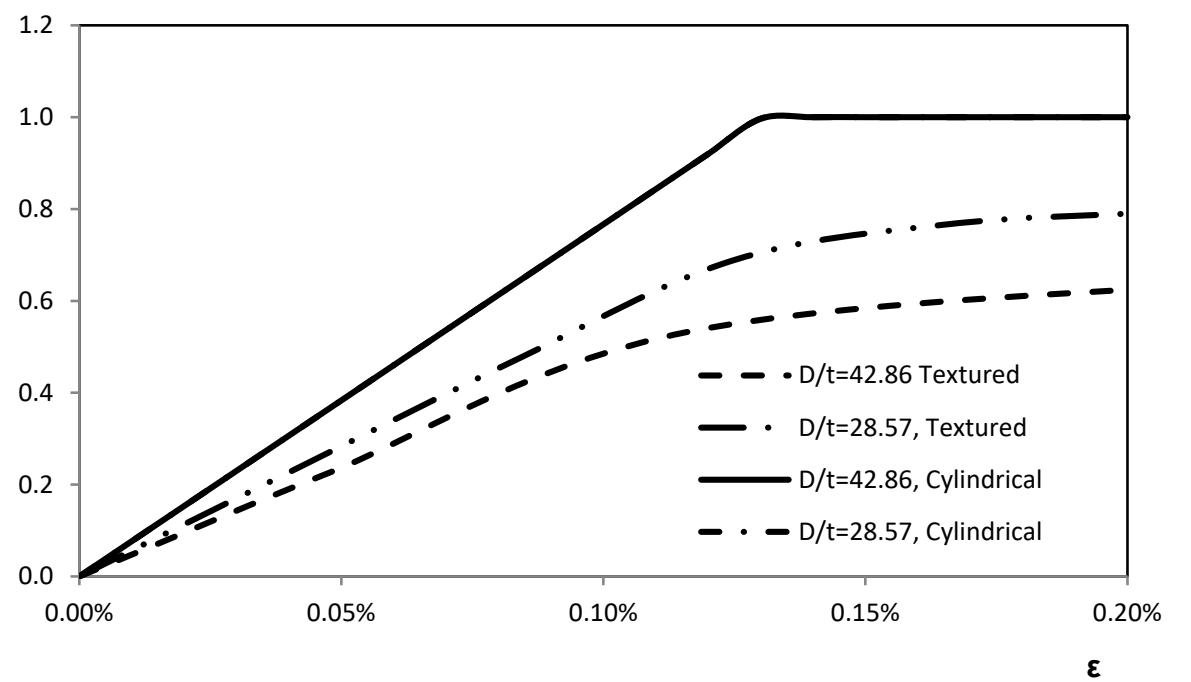

(a)

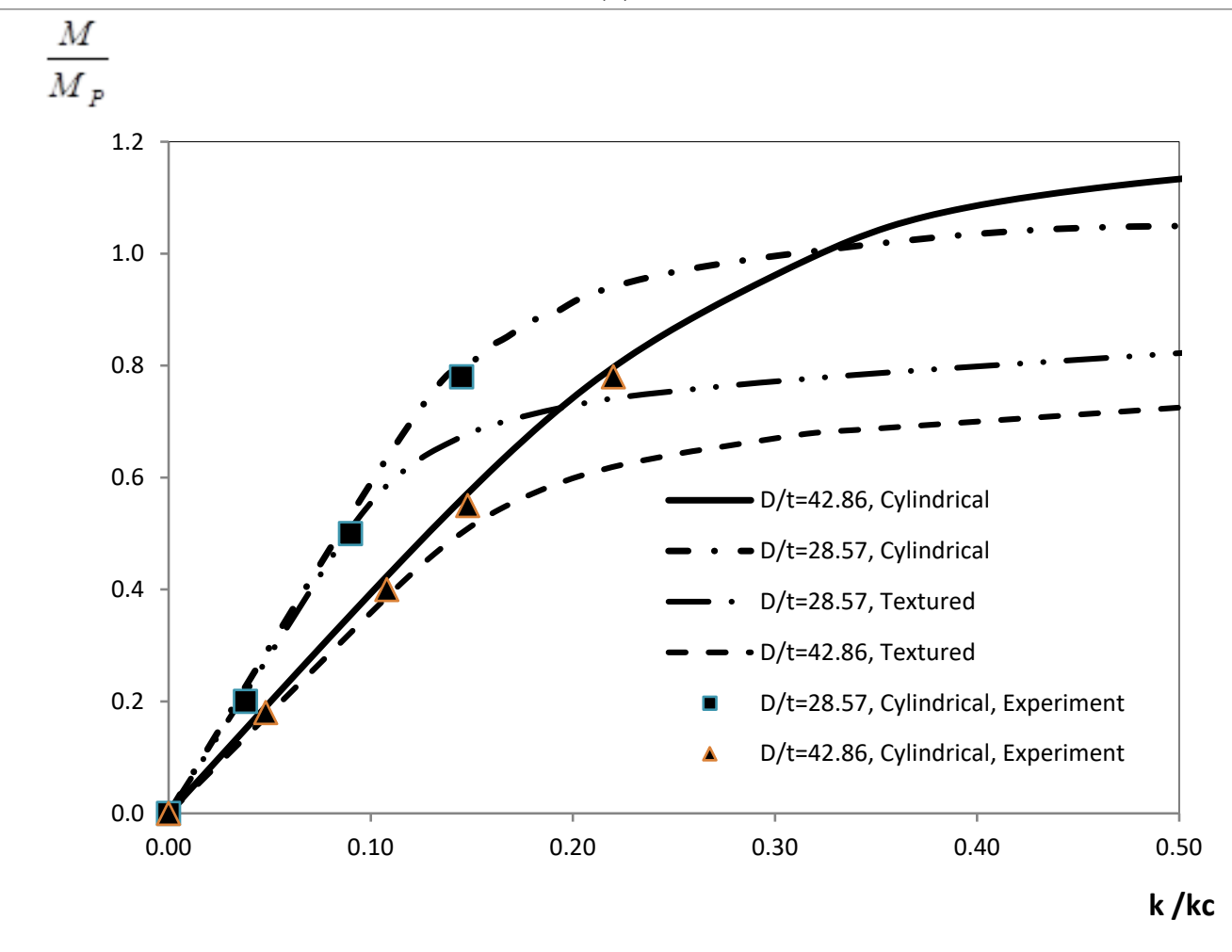

(b)

Figure 3 


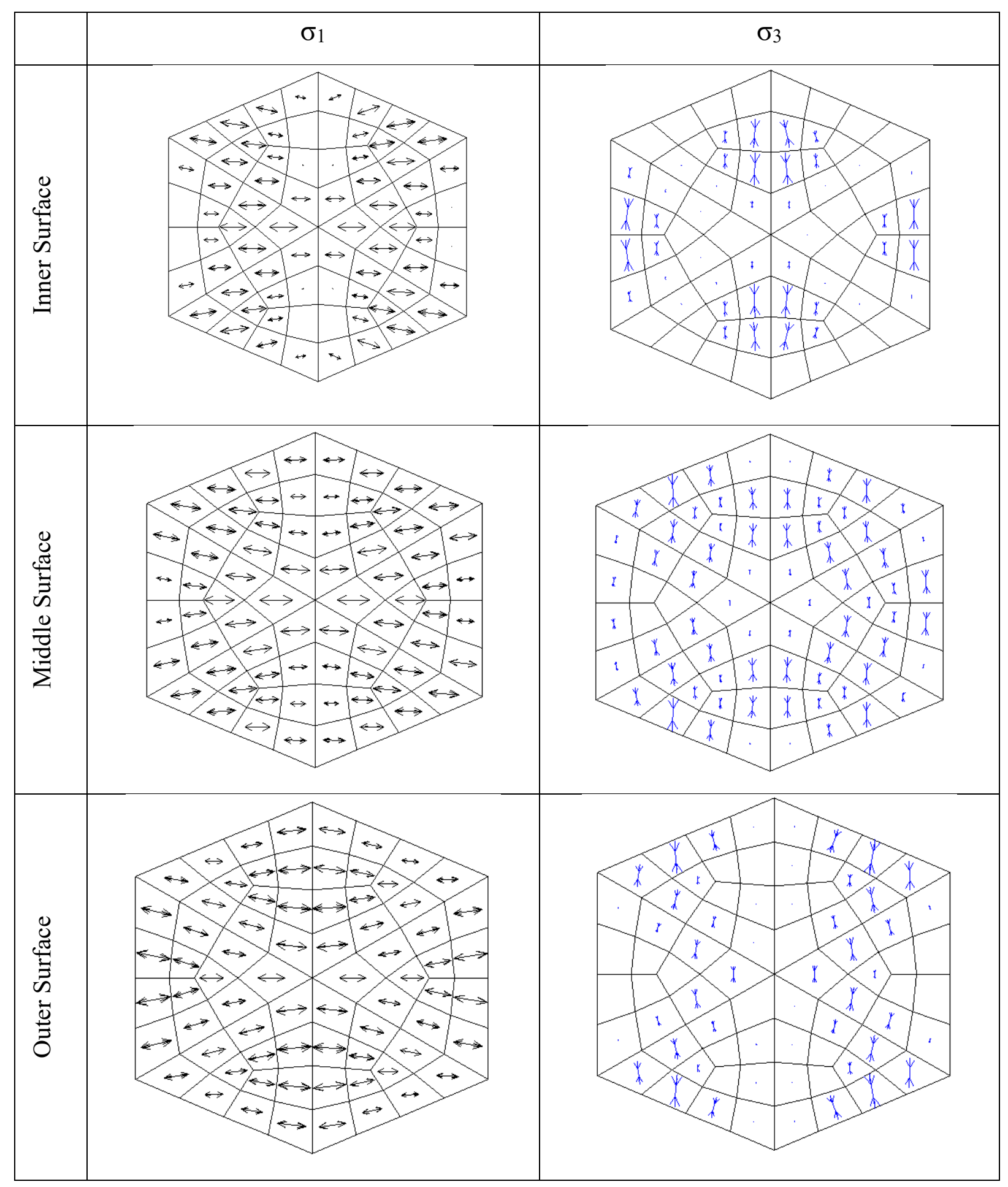



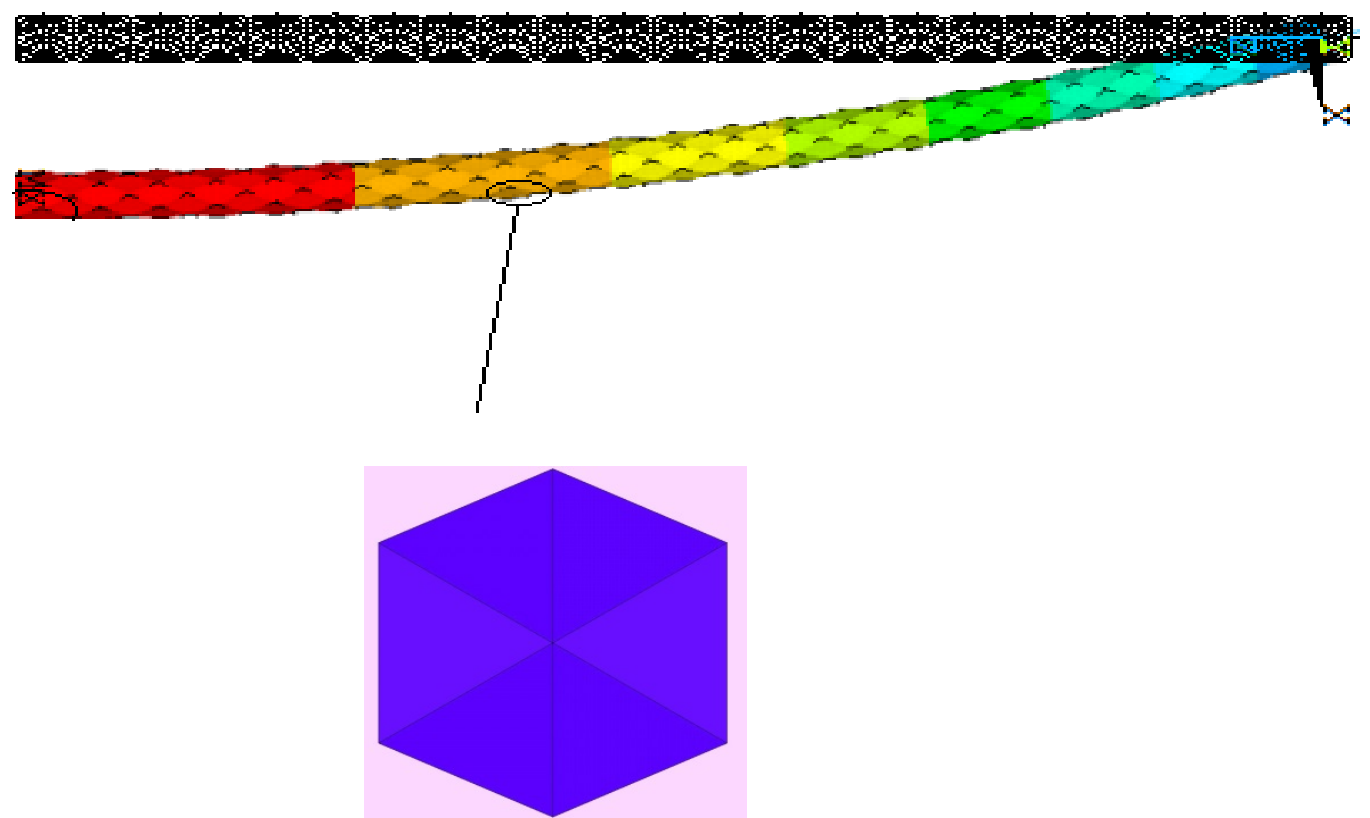

Figure 4 


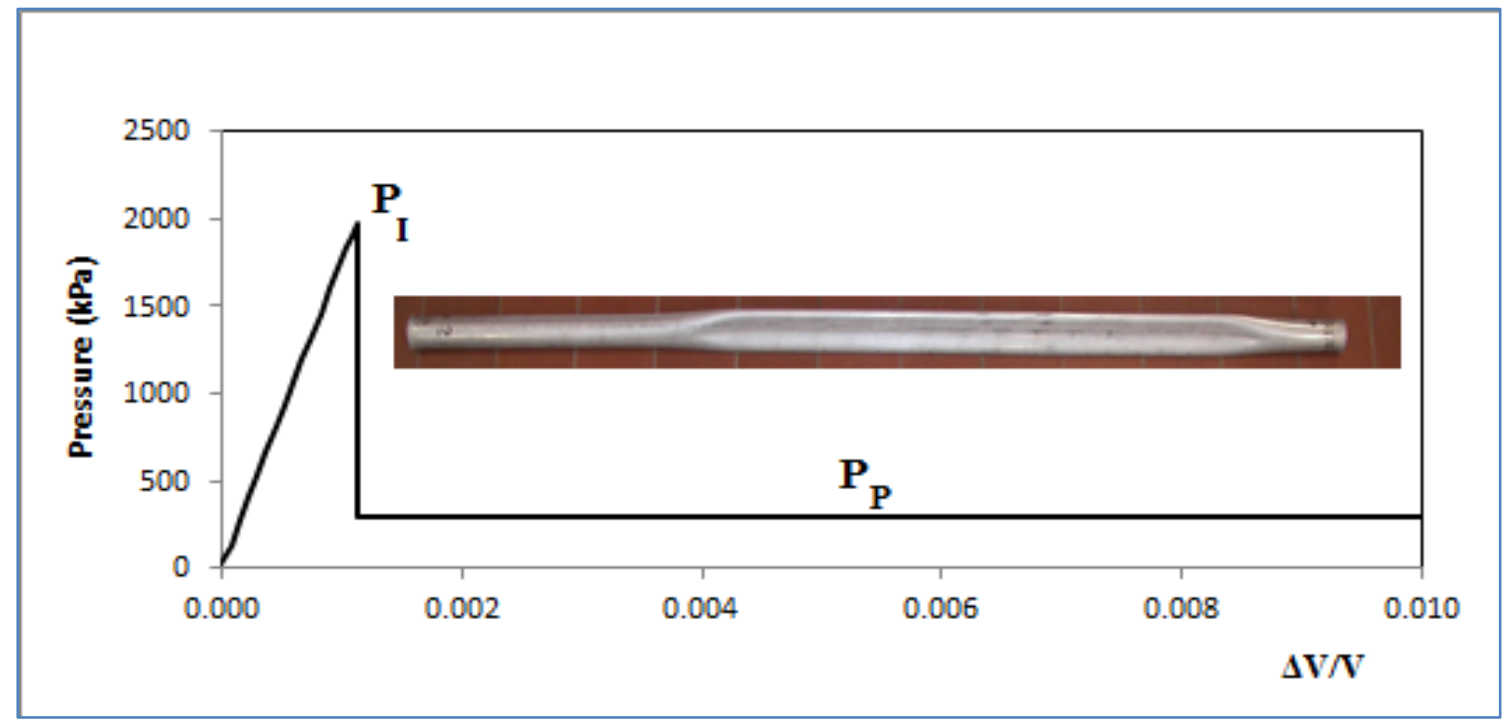

Figure 5 


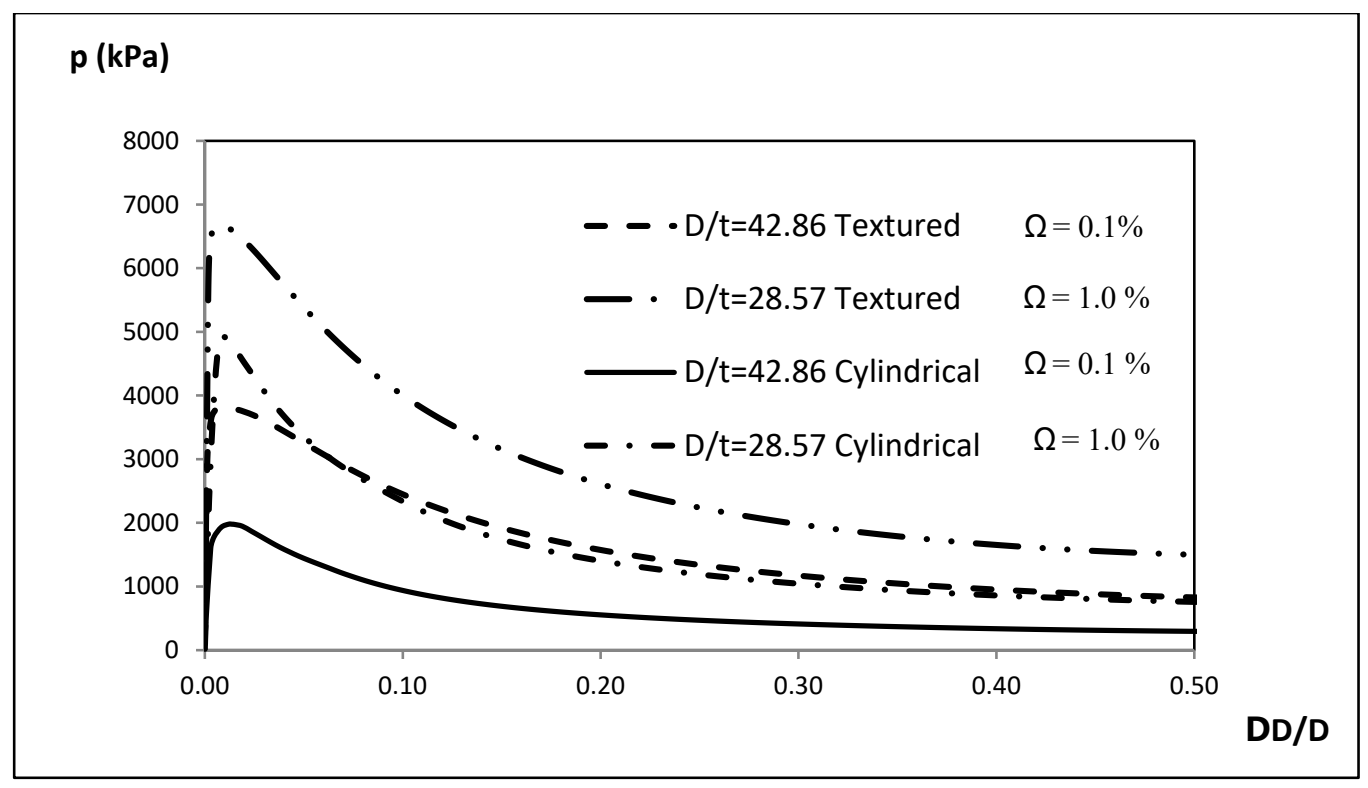

Figure 6 


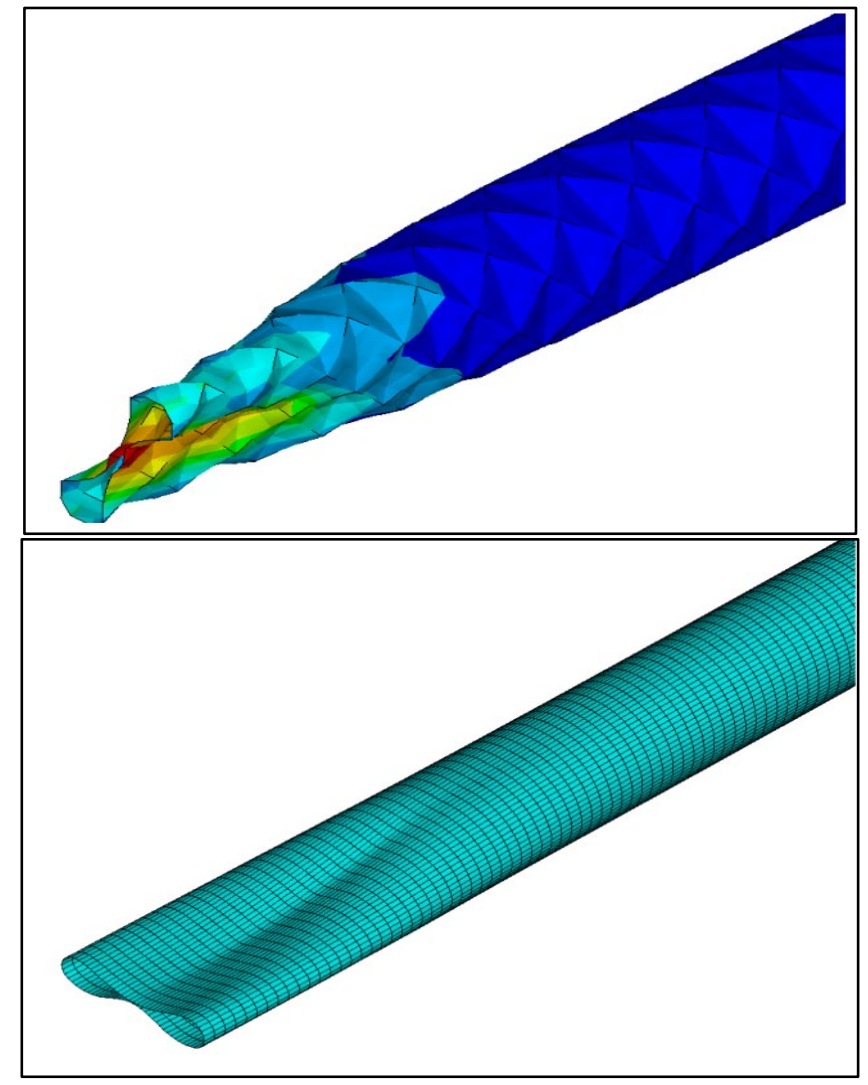

Figure 7 


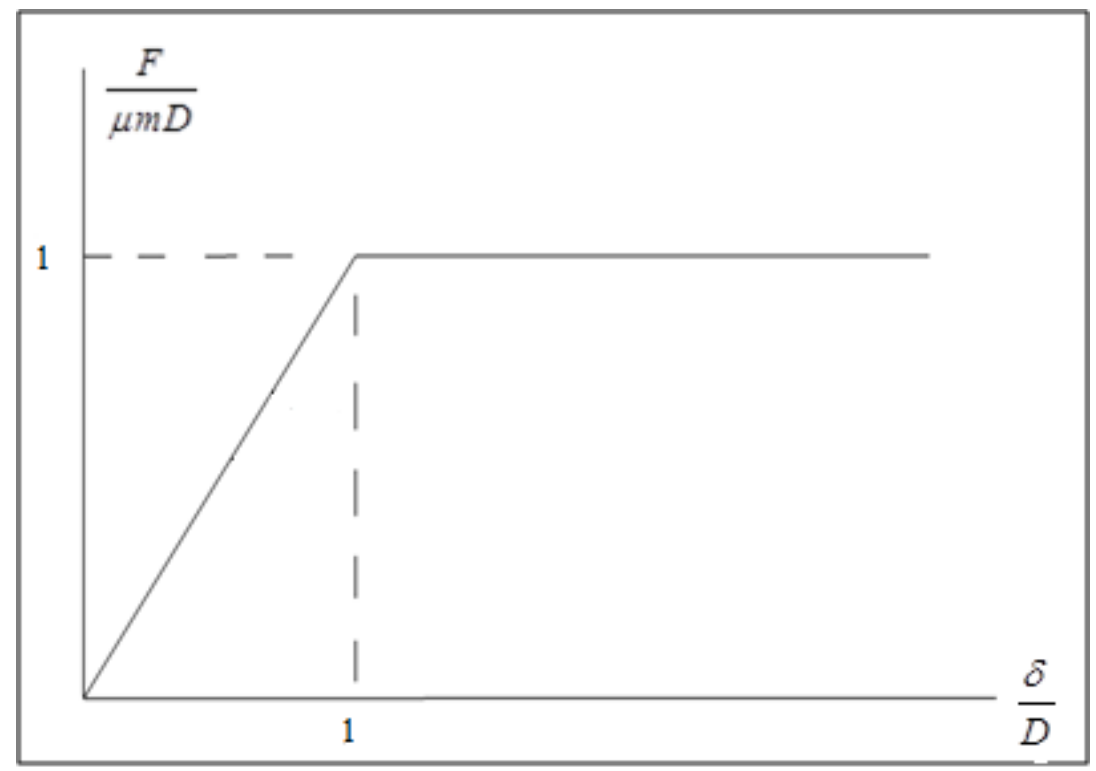

Figure 8 


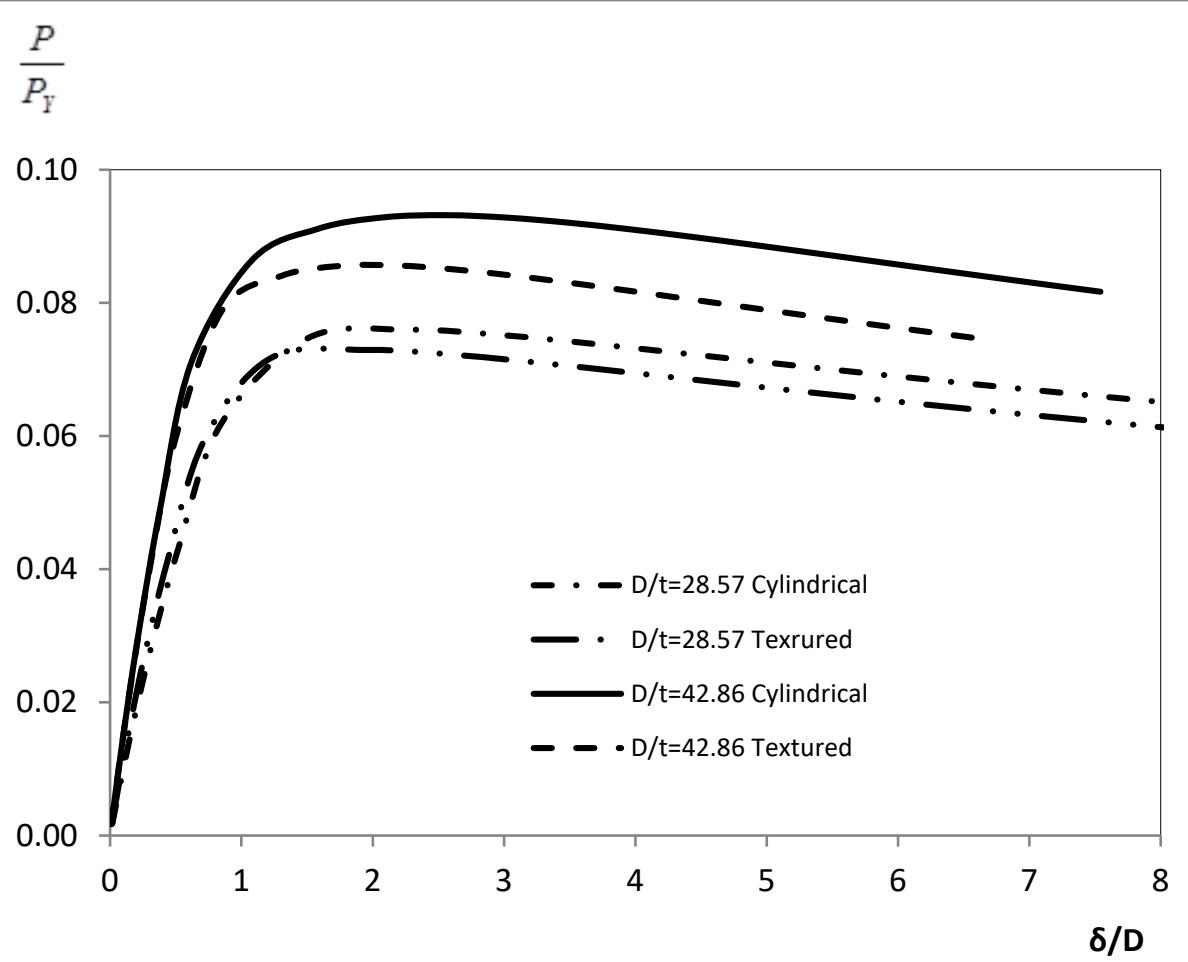

(a)

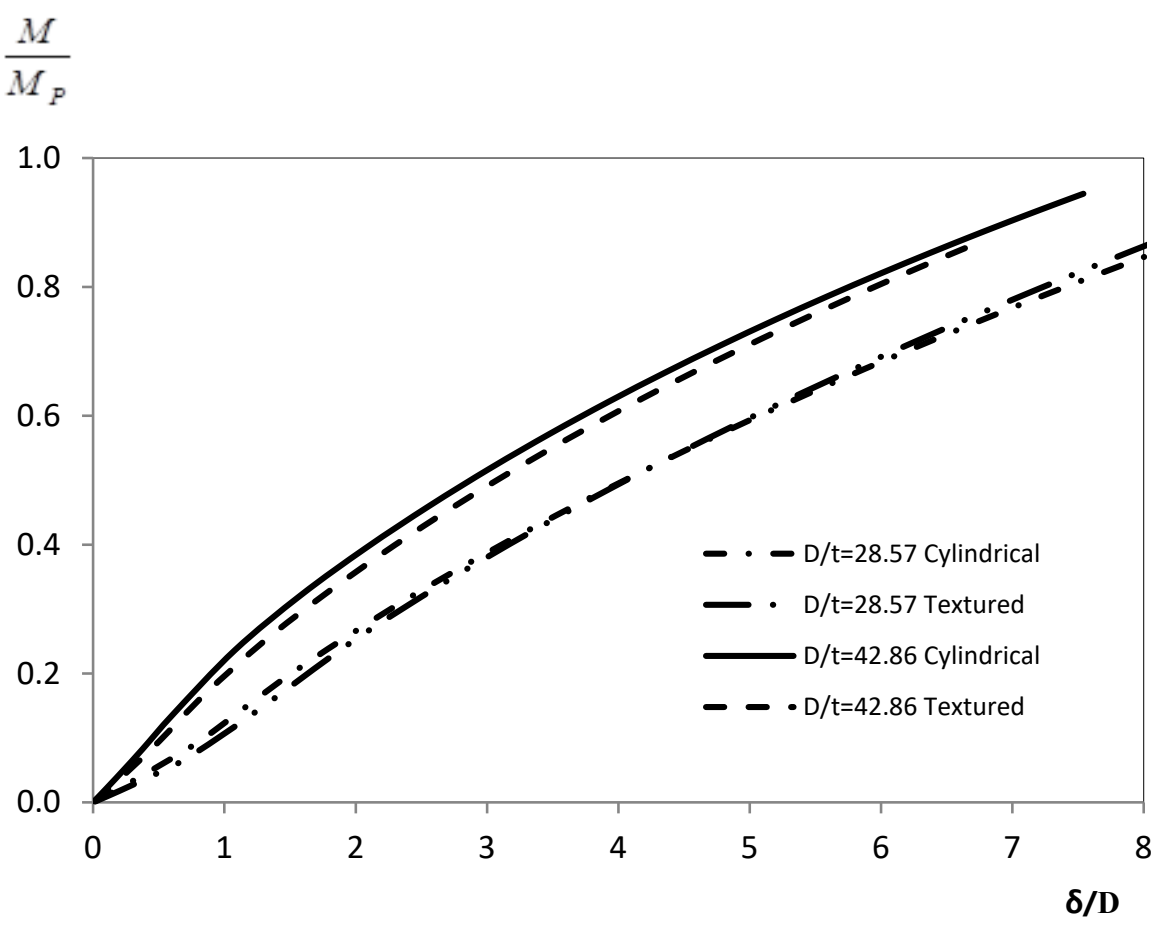

(b)

Figure 9 


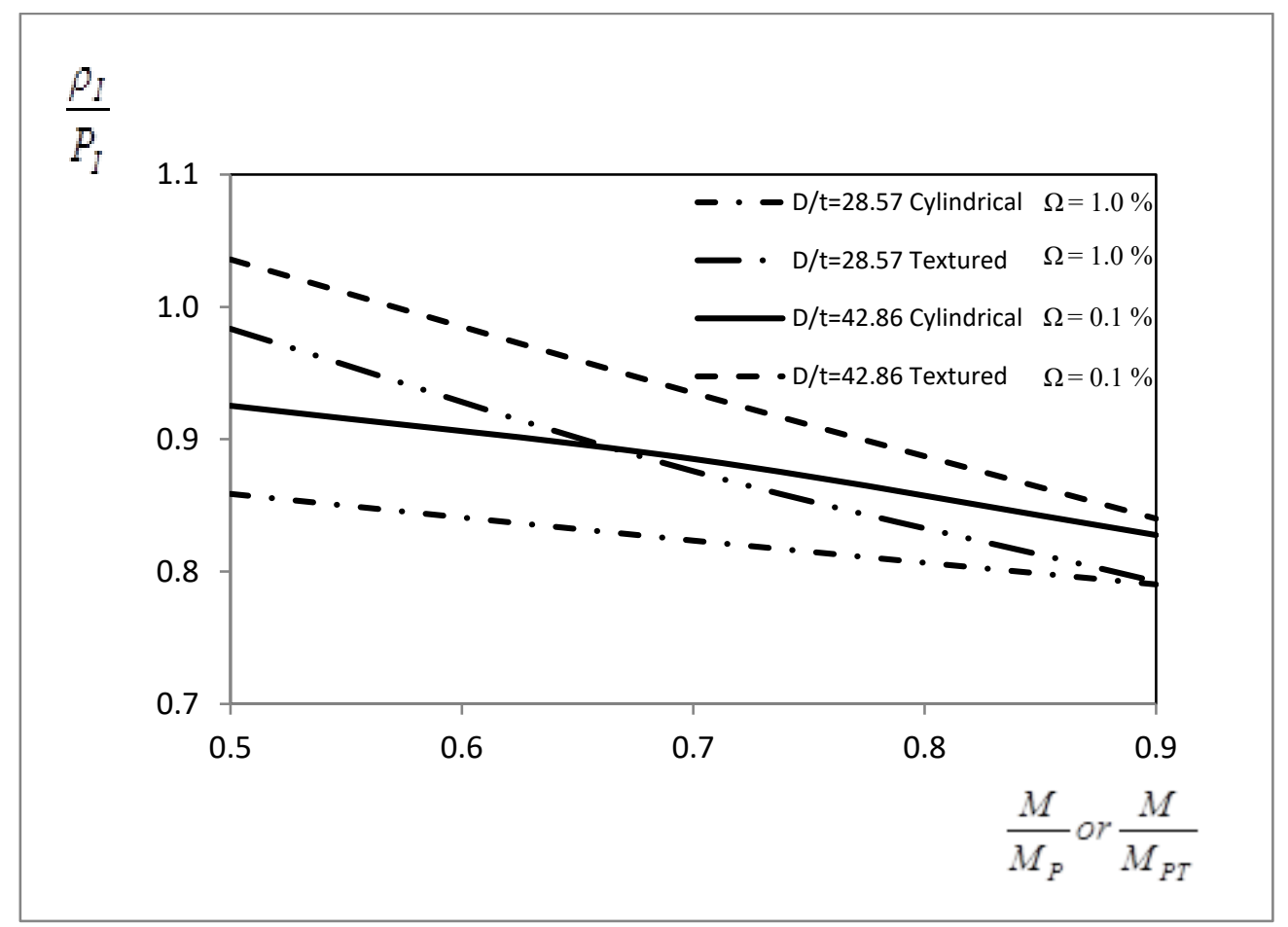

Figure 10 

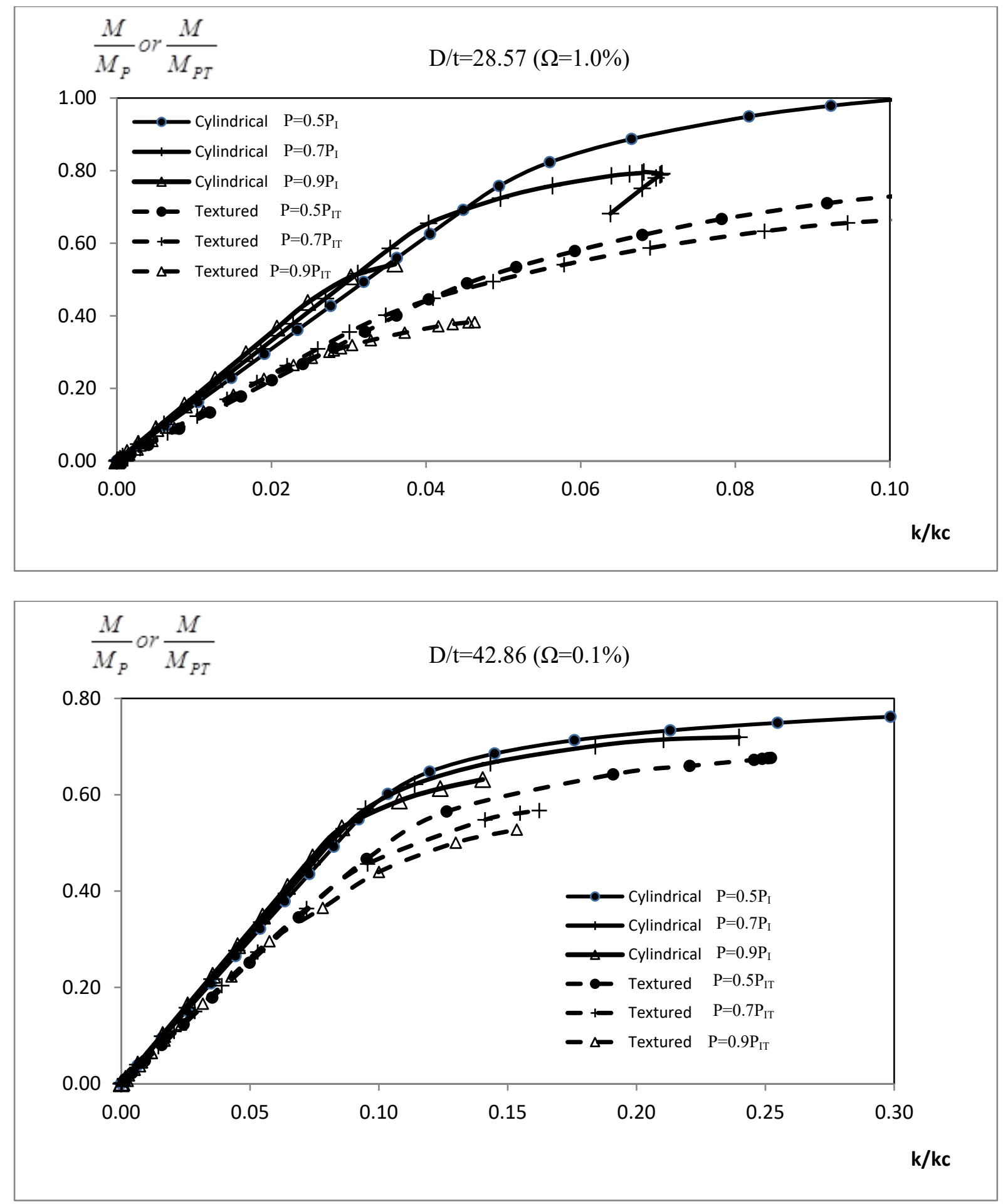

Figure 11 
$\frac{p}{P_{I}}$ or $\frac{p}{P_{I T}} \quad \mathrm{D} / \mathrm{t}=28.57(\Omega=1.0 \%)$

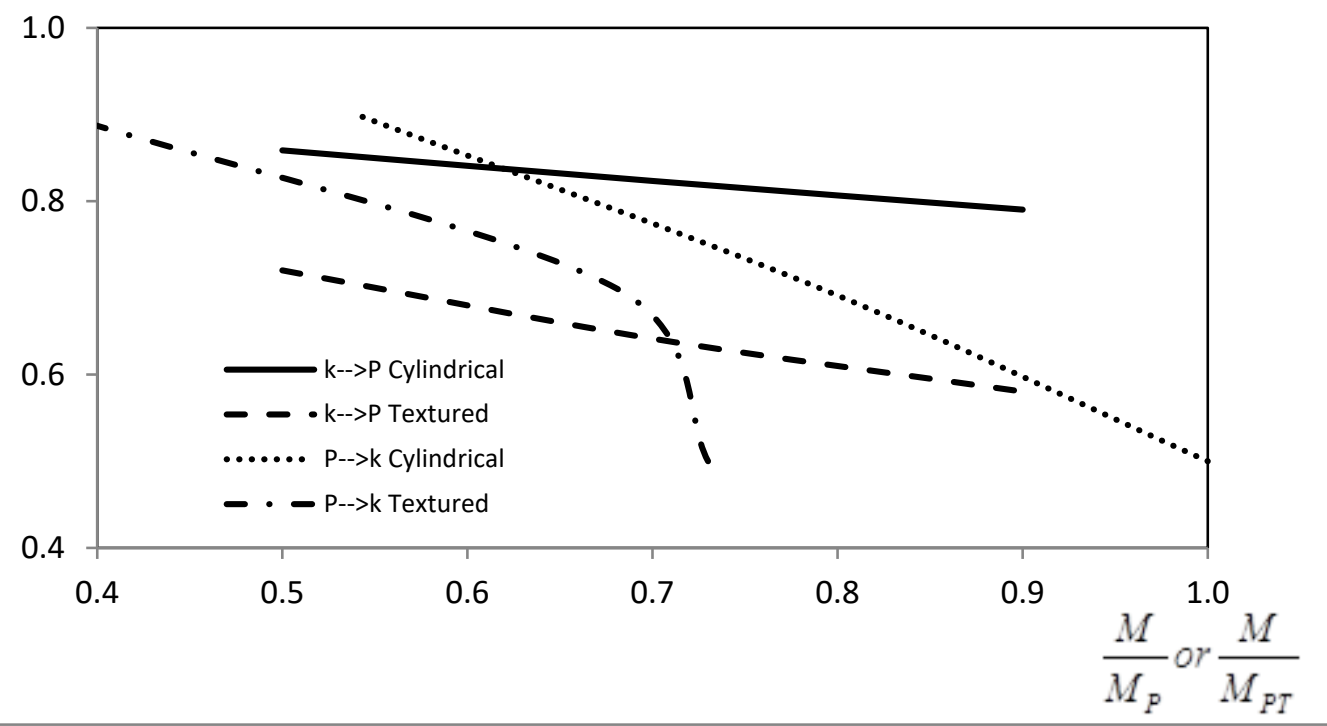

$\frac{p}{P_{I}}$ or $\frac{p}{P_{I T}} \quad \mathrm{D} / \mathrm{t}=42.86(\Omega=0.1 \%)$

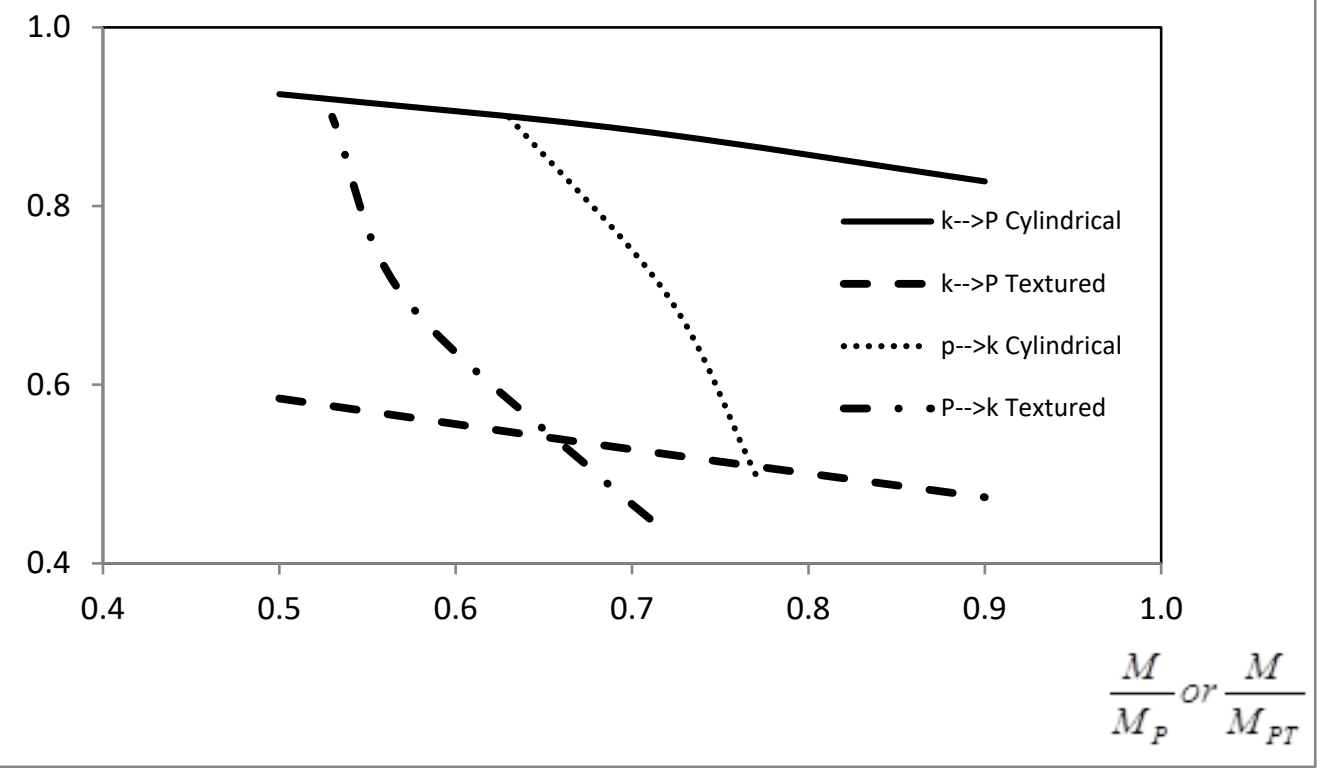

Figure 12 